\title{
The role of vitamin $D$ in perinatology. An up-to-date review
}

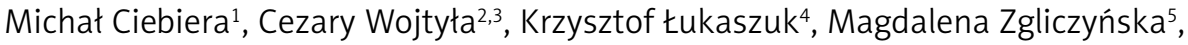 \\ Kornelia Zaręba ${ }^{2}$, Wojciech Rawski², Grzegorz Jakiel²
}

\author{
${ }^{1}$ Second Department of Obstetrics and Gynecology, Center of Postgraduate Medical \\ Education, Warsaw, Poland \\ ${ }^{2}$ First Department of Obstetrics and Gynecology, Center of Postgraduate Medical \\ Education, Warsaw, Poland \\ ${ }^{3}$ European Observatory of Health Inequalities, State University of Applied Sciences, \\ Kalisz, Poland \\ ${ }^{4}$ Department of Obstetrics and Gynecological Nursing, Faculty of Health Sciences, \\ Medical University of Gdansk, Gdansk, Poland \\ ${ }^{5}$ Students' Scientific Association at the First Department of Obstetrics and \\ Gynecology, Medical University of Warsaw, Warsaw, Poland
}

Submitted: 2 March 2018; Accepted: 5 July 2018

Online publication: 30 January 2019

Arch Med Sci 2021; 17 (4): 992-1005

DOI: https://doi.org/10.5114/aoms.2019.81747

Copyright @ 2019 Termedia \& Banach

\section{Abstract}

The role of vitamin $D$ in perinatology is a subject of major interest in current medicine. There is growing evidence about the role of maternal vitamin D levels in pregnancy outcomes. The aim of this review is to summarize the current literature about the role of vitamin $D$ in perinatology. Evidence from this review suggests associations between low levels of maternal vitamin $D$ and higher risk of certain obstetrical complications. Vitamin $D$ has been found to be related to preeclampsia, gestational diabetes mellitus, low birth weight, and preterm birth. The current literature supports vitamin D supplementation in pregnant women, but more high-quality data are necessary. The problem that remains is how to achieve an optimal 25-hydroxyvitamin D level. To determine the real benefits of vitamin $D$ supplementation in pregnancy, we need high-quality trials in larger groups.

Key words: gestational diabetes mellitus, low birth weight, preeclampsia, preterm birth, vitamin D.

\section{Introduction}

Vitamin D - overview, sources, and metabolism

Vitamin D, also known as calciferol, is a fat-soluble steroid (a prohormone) playing an important role in various metabolic and physiological pathways [1-4]. Vitamin D is crucial in the regulation of calcium homeostasis, especially in bones, where it promotes mineralization [5-7]. Vitamin D receptors are present all over the human body, from bones and muscles to the central nervous system $[8,9]$. The main source of vitamin D for the body is sunlight exposure, but it can also be extracted from diet or food supplements. Fish, fish oils, and dietary supplements enriched with vitamin $D$ are valuable sources of this vitamin $[10,11]$. Vitamin $D$ may be found in two forms: ergocalciferol (vitamin $D_{2}$ ) and cholecalciferol (vitamin $D_{3}$ ) [12]. Vitamin $D_{2}$ is obtained from plants, whereas vitamin $D_{3}$ is synthe-

\author{
Corresponding author: \\ Michat Ciebiera MD, PhD \\ Second Department \\ of Obstetrics \\ and Gynecology \\ Center of Postgraduate \\ Medical Education \\ 80 Cegłowska St \\ 01-809 Warsaw, Poland \\ Phone: +48 607155177 \\ E-mail: michal.ciebiera@ \\ gmail.com
}


sized in the sunlight-exposed skin from 7-dehydrocholesterol under ultraviolet $B$ radiation [2, 13-15]. Vitamin $D$ bound to vitamin $D$ binding protein is transported to the liver where it is hydroxylated to 25 -hydroxyvitamin D $(25(\mathrm{OH}) \mathrm{D})[15,16]$. The next hydroxylation takes place in the kidneys, where $25(\mathrm{OH}) \mathrm{D}$ is converted into 1,25 -dihydroxyvitamin D $\left(1,25(\mathrm{OH})_{2} \mathrm{D}\right)$, the active form of vitamin $\mathrm{D}$ [14-16].

\section{Vitamin D - serum concentration values}

According to available scientific data, the level of serum vitamin $D$ concentration is best reflected by $25(\mathrm{OH}) \mathrm{D}$, due to its long life and stability $[3,17]$. The values defining vitamin $D$ deficiency are the subject of a heated debate among experts, and probably no consensus will be reached in the near future. According to the Endocrine Society and its official guidelines, vitamin $D$ deficiency is defined as a serum level of $25(\mathrm{OH}) \mathrm{D}$ lower than $20 \mathrm{ng} / \mathrm{ml}$, whereas vitamin D insufficiency is a serum level of 25(OH)D from 21 to $29 \mathrm{ng} / \mathrm{ml}$. The level of vitamin $\mathrm{D}$ which can be defined as sufficient is set at $30 \mathrm{ng} / \mathrm{ml}[4,18]$. It is believed that the calcium absorption is optimal at this level [3, $4,18]$. According to the latest review by Holick, the ultimate goal should be to keep the $25(\mathrm{OH}) \mathrm{D}$ serum level above $30 \mathrm{ng} / \mathrm{ml}$, with the preferred range being 40-60 ng/ml [4] (Table I).

\section{Vitamin D deficiency - a worldwide problem}

Several studies have revealed that vitamin D deficiency is a worldwide problem in all people regardless of their age, sex, or social status $[1,19,20]$. What is already known is that the main causes of vitamin $D$ deficiency in female populations are incorrect supplementation and insufficient exposure to sunlight (e.g. due to spending most of their time in closed rooms or living in northern lands) $[3,10,11,21,22]$. Factors influencing lower photon absorption (thus reducing the conversion of vitamin D to the skin) are older age, sunscreens, low sun exposure, geographical latitude, winter season, and increased skin pigmentation [23]. The latter factor is particularly important for African Americans, in which skin melanin content is much higher than that of other races [24, 25].

According to studies performed by Palacios et al., pregnant and lactating women showed a high incidence of vitamin $D$ deficiency $[26,27]$. The problem of reduced vitamin $\mathrm{D}$ level and its association with many childhood and adult diseases is well known and its importance has finally come to the consciousness of both physicians and patients [28]. In current medicine, awareness about the detection of vitamin $\mathrm{D}$ deficiency in pregnant women remains a problem $[29,30]$. While vitamin $D$ serum status examination and supplementation in newborns and in older children is a daily practice, it is often a treated as a secondary problem in pregnant women.

\section{Vitamin D - role in pathophysiology}

Vitamin D is an important link in inflammatory pathways [31]. It regulates immunological, circulatory and neurological processes [3, 32-36]. In adults (but also in the perinatal period) vitamin $D$ regulates the immune system and is an anti-inflammatory agent that slows down the expression of pro-inflammatory cytokines and chemokines such as tumor necrosis factor $\alpha$ (TNF- $\alpha)$, interferon $\gamma($ INF- $\gamma$ ), and interleukin 6 (IL-6) [31, 34, 37-39]. Steroid hormones (e.g., estrogens and progesterone) and human chorionic gonadotropin (HCG) are also connected with vitamin $D$ pathways according to several available studies $[38,40]$.

The active metabolites of vitamin $D$ have broad and diverse biological functions. According to older and recent reports, vitamin D deficiency is widely associated with many different conditions (e.g., type 1 diabetes mellitus, malignant neoplasms, cardiovascular diseases, etc.) [3, 33, 35, 41-43]. Other illnesses, which are not less important, are chronic kidney disease (kidney failure), gastrointestinal illnesses, and liver failure [41, 44].

\section{Vitamin D - role in uncomplicated pregnancy}

Vitamin D plays a major role in human reproduction. The effect of vitamin $D$ on pregnancy is a subject of major interest in current medicine. Vitamin D influences folliculogenesis, modulates endometrial receptivity, and regulates embryogenesis [45]. It plays an important role in trophoblast invasion [46]. There are plenty of studies that prove its effects on placental implantation, angiogenesis and endothelial function, immune function, inflammatory response during pregnancy, oxidative stress, and glucose homeostasis [47-53]. According to Hollis and Wagner, vitamin D plays an important role in embryo and fetal skeletal development [54]. The most important role of vitamin $D$ during pregnancy is to elevate placental calcium transport [55]. Vitamin D status during pregnancy relies mostly on the maternal stores [27]. During pregnancy, mobilization of

Table I. Serum vitamin D concentration status in humans - classification

\begin{tabular}{|lc|}
\hline Condition & $\begin{array}{c}\text { 25(OH)D serum } \\
\text { concentration }[\mathrm{ng} / \mathrm{ml}]\end{array}$ \\
\hline Vitamin D deficiency & $\leq 20$ \\
\hline Vitamin D insufficiency & $21-29$ \\
\hline Vitamin D sufficiency & $\geq 30$ \\
\hline Optimal vitamin D status & $40-60$ \\
\hline
\end{tabular}


maternal calcium increases to ensure adequate fetal bone mineralization [55]. 25(OH)D is a metabolite that crosses the placental barrier and is the main form of vitamin D used by the fetus [5658]. Appropriate $25(\mathrm{OH}) \mathrm{D}$ serum concentrations are important to sustain the increased levels of $1,25(\mathrm{OH}) 2 \mathrm{D}$ during pregnancy $[27,59] .1,25(\mathrm{OH})_{2} \mathrm{D}$ serum levels increase in early pregnancy and continue to grow until delivery [60]. Park et al. very recently reported that higher maternal vitamin $\mathrm{D}$ serum biomarker levels (maternal free $25(\mathrm{OH}) \mathrm{D}$ and $\left.24,25(\mathrm{OH})_{2} \mathrm{D}\right)$ might be connected with attenuated bone resorption during the third trimester and proper calcium delivery to the fetus [61].

\section{Vitamin D and pathophysiology of pregnancy}

There is growing interest in the effect of maternal vitamin D concentrations on pregnancy outcomes [62]. Maternal vitamin D status is proved to be associated with various obstetrical outcomes, such as early miscarriages, but also in the pathophysiology of other important obstetric complications [63-65]. The studies on vitamin D intake and its role in protection against adverse pregnancy outcomes differ, but there are still no large randomized control trials (RCTs) or clear guidelines regarding this problem $[49,55,66]$. One good available RCT, by Hollis et al., included women with a singleton pregnancy at 12 to 16 weeks' gestation who received different daily doses of vitamin D until delivery [59]. There are still many contradictory opinions.

There are studies that suggest the increase of vitamin $\mathrm{D}$ deficiency in pregnant women and its connection with adverse pregnancy outcomes (maternal, fetal and in child) such as preeclampsia, gestational diabetes mellitus (GDM), preterm birth, low birth weight, impaired neurodevelopment, asthma development or future problems with body composition [49, 66-70]. As these four (preeclampsia, GDM, preterm birth and low birth weight) are the major problems in perinatology, and vitamin $\mathrm{D}$ deficiency during the perinatal period is one of the most common healthcare problems worldwide [27, 49, 71, 72], we decided to review available literature in this field.

The aim of this review is to summarize the current literature about the role of vitamin $D$ in perinatology at the beginning of the year 2018 . We have focused on preeclampsia, GDM, preterm birth, and low birth weight - the four major problems in current perinatology - and their relationship with vitamin D.

\section{Material and methods}

This article presents an up-to-date review of publications about the current role of vitamin $D$ in perinatology. The main aim of our review was to critically review the influence of vitamin $D$ in pregnancy and limited birth outcome (low birth weight). A literature search for this review was conducted in PubMed of the National Library of Medicine using the following keywords: "vitamin D", "preeclampsia”, "gestational diabetes", "preterm birth", "intrauterine growth restriction", and "low birth weight". The above keywords were chosen to reflect the four major issues in current perinatology that influence both mother and fetus. The above problems are those that can be diagnosed during pregnancy and in the case of detection, a treatment attempt can be implemented. The other vitamin $\mathrm{D}$ related birth outcomes such as wheezing, asthma, autism, rickets, etc. were excluded due to the lack of possible diagnosis during pregnancy. During our search we combined the keywords into pairs, which resulted in: "vitamin D" and "preeclampsia" - 307 publications; "vitamin D" and "gestational diabetes" 274 publications; "vitamin D" and "preterm birth" - 374 publications; "vitamin D" and "intrauterine growth restriction" - 41 publications; "vitamin D" and "low birth weight" - 368 publications. If the search was duplicated the papers were excluded. We selected papers that concerned the influence of vitamin D on selected pregnancy outcomes. The results of relevant original studies and reviews published in the English language up to May 2018 have been summarized and discussed in this consistent review. Additional different types of articles and reviews were considered when relevant.

There are many differences in methods to assess serum 25(OH)D and there might be some inconsistencies related to this when comparing different trials [73-75]. This is why some results should be interpreted with caution.

It might also be pointed out that according to recent findings vitamin $D$ RCTs should be based on 25(OH)D concentrations, not vitamin D dose as proposed by Grant et al., who proposed an observational approach to vitamin D RCTs' design, based on serum 25(OH)D concentration. That can prevent mistakes related to ultraviolet B (UVB) exposure and non-vitamin D molecular mechanisms [76].

\section{Discussion}

\section{Preeclampsia}

Preeclampsia is a pathological condition of pregnancy complicated by hypertension (high blood pressure), proteinuria, and coexisting dysfunction of selected organs (e.g., liver, blood, and kidneys) or other pregnancy complications (e.g., intrauterine growth restriction) $[77,78]$. The incidence is estimated to be between 3\% and 10\% of all pregnancies $[77,79]$. It is associated with adverse perinatal outcomes and can cause long- 
term complications in both mother and fetus [78]. Even in the age of better perinatal care, it is still a leading cause of maternal death [79].

Abnormal maternal spiral artery remodeling during trophoblast invasion is believed to be the major cause of preeclampsia [77, 80]. There is still conflicting evidence whether vitamin D deficiency in pregnancy is associated with preeclampsia. The pathogenesis of preeclampsia involves a number of biological processes (e.g., inflammation, immunity, immune response, and angiogenesis) all of them might be vitamin D-dependent [27]. According to the study by Chan et al., vitamin D promotes extravillous trophoblast invasion [81]. Increased catabolism and abnormal placental uptake of $25(\mathrm{OH}) \mathrm{D}$ are believed to be associated with preeclampsia [82]. An interesting study from Australia revealed that the highest incidence of hypertensive disorders in pregnancy was associated with pregnancies giving birth in winter (low sun exposure) [83]. Vitamin D has been shown to be involved in gene regulation and expression signaling in early placental development [84]. Vitamin D plays a critical role in angiogenesis and oxidative stress control, which might be crucial in its relationship with preeclampsia [85-87]. Vitamin $D$ has also been found to regulate angiogenesis with an influence on vascular endothelial growth factor genetic pathways. In the study by Schultz et al., vitamin D was found to be associated with the expression of soluble fms-like tyrosine kinase-1 (sFlt-1) and vascular endothelial growth factor [88]. An interesting observation was that a maternal status of $>40 \mathrm{ng} / \mathrm{ml}$ can have an impact on related gene transcription and potentially decrease antiangiogenic factors that may result in better placentation [88]. According to Jia et al., $1,25(\mathrm{OH})_{2} \mathrm{D}$ plays a major role in placental vasculature by relaxing smooth muscle cells [89]. In a study by Chinese scientists, $1,25(\mathrm{OH})_{2} \mathrm{D}$ was found to play a major role in reducing apoptosis in ischemic placentas. It was concluded that vitamin D might have potential anti-preeclampsia protection properties [90].

Robinson et al. investigated the association between low maternal vitamin $\mathrm{D}$ status and early, severe preeclampsia [91]. In their results, total 25(OH)D was decreased at the moment of diagnosis of early onset preeclampsia. A year later they published a study where they found lower 25(OH)D serum levels in patients with early onset preeclampsia with abnormal fetal growth in comparison to patients with preeclampsia and normal fetal weight [92]. One of the major facts that can be established from several studies is that an increased risk for preeclampsia is reported in women with vitamin $D$ deficiency (serum levels under $20 \mathrm{ng} / \mathrm{ml})[64,65,93,94]$. The findings of other observational studies on vitamin $D$ and preeclampsia are mixed. Some of them show an association between lower vitamin D serum levels and increased risk of preeclampsia [95-97], whereas others refute this association [98, 99]. The conflicting results are likely due to the differences in study design, different populations, geographic latitude, vitamin D measurement, and other factors [100]. In the PREvitD case-control study, low maternal 25(OH)D serum levels were associated with increased risk of preeclampsia, but after adjustment the authors concluded that there is a high probability that this is not a causal association [101]. According to the study by Bodnar et al., vitamin $D$ deficiency may be a risk factor for severe preeclampsia, but it is not associated with preeclampsia overall [96]. Palacios et al. reviewed several studies and (based on their data) confirmed that vitamin D deficiency is significantly associated with an increased risk of preeclampsia [27]. A very recent systematic review and meta-analysis by Akbari et al. found that women with vitamin D deficiency (serum levels lower than $20 \mathrm{ng} / \mathrm{ml}$ ) are at higher risk of preeclampsia [102]. On the other hand, a meta-analysis of Spanish studies by Martinez-Dominguez et al. failed to confirm this dependence [103]. What about supplementation? A D-tect study from Denmark, which included more than 73000 women (years 1983-1988), presented data indicating that fortified margarine (1.25 $\mu \mathrm{g}$ vitamin D/100 g margarine) did not influence the total risk of preeclampsia in any of the studied groups [104]. However, what is even more interesting, additional vitamin D supplementation in fetal life reduced the risk of preeclampsia later in life [105]. The study by Haugen et al. based on a group of more than 23000 women found that proper vitamin D supplementation reduces the risk of preeclampsia by $27 \%$ [106]. According to Robinson et al., an increase in maternal serum of $10 \mathrm{ng} / \mathrm{ml}$ of $25(\mathrm{OH}) \mathrm{D}$ reduces the possible risk of preeclampsia [92]. A recent study by Naghshineh also found a lower frequency of preeclampsia in pregnant women who received vitamin D supplementation in comparison to controls, but without statistical significance [87]. Additionally, a recent systematic review by Purswani et al. found that vitamin D supplementation did not have an independent effect on preeclampsia prevention [107]. In our opinion, these doubts should be resolved by future high-quality, well-designed studies on larger groups.

\section{Gestational diabetes mellitus}

Gestational diabetes mellitus is a pathological condition in the pregnancy period in which a woman without diabetes develops hyperglycemia (high blood sugar levels) [108]. Pregnancy confers a state of insulin resistance and hyper- 
insulinemia. The GDM is considered to share the same pathogenesis pathway as type 2 diabetes mellitus. The risk factors for GDM are being overweight, GDM in previous pregnancies, a positive family history of type 2 diabetes mellitus, and polycystic ovarian syndrome [108]. Vitamin D receptor and $1 \alpha$-hydroxylase have been found in the placenta, suggesting that they play a role in its metabolism $[81,109]$. How does vitamin D deficiency influence GDM occurrence? There are several pathways [53], but the most important are calcium pool dysregulation in the pancreas, an effect on insulin sensitivity and responsiveness, interactions of vitamin D with the insulin-like growth factor (IGF) system and inflammation generation [109].

Low serum levels of $25(\mathrm{OH}) \mathrm{D}$ have been related to the risk of developing type 2 diabetes in women [110]. Vitamin D deficiency is associated with impaired glucose tolerance and diabetes in the general population $[111,112]$. The recent meta-analysis by Akbari et al. demonstrated that vitamin D supplementation might lead to an improvement in insulin resistance parameters (e.g., improvement in insulin resistance index and low-density lipoprotein cholesterol levels) [113]. Quite similar results were obtained in the recent study by Maktabi et al. where vitamin D supplementation had beneficial effects on glucose-related parameters in patients with polycystic ovarian syndrome [114].

There has been increasing evidence about the role of vitamin $D$ in modifying the risk of GDM [109]. Maternal 25(OH)D serum levels have been found to be related to the risk of GDM in various studies $[95,115,116]$. Bener et al. in their study on 1873 women found that vitamin D deficiency was significantly associated with higher risk of GDM occurrence [95]. In the studies by Lacroix et al. and McManus et al., the positive relationship between low 25(OH)D serum levels and GDM was also proven $[117,118]$. Similar observations were made by Al-Ajlan et al. in Saudi Arabian women [119]. There are some well-performed systematic reviews and meta-analyses about the above-mentioned problem - in both of them lower vitamin $D$ levels were found to be associated with the increased risk of developing GDM [65, 120-123]. According to the meta-analysis by Palacios et al., vitamin $D$ deficiency in early pregnancy was associated with elevated risk of developing GDM [27]. The meta-analysis by Zhang et al. found that low blood vitamin D level increases the risk of GDM, while vitamin D supplementation during pregnancy reduces the risk of GDM occurrence [123]. In a meta-analysis by $\mathrm{Hu}$ et al. 4,634 women diagnosed with GDM showed that maternal vitamin D insufficiency was associated with increased risk of GDM by $39 \%$ [122]. The results obtained by Casey et al. from an Irish population found weak associations between 25(OH)D serum levels and markers of glucose and insulin metabolism [28]. A study by Hauta-Alus et al. found that a maternal vitamin D status specified as $25(\mathrm{OH}) \mathrm{D}$ serum level above $20 \mathrm{ng} / \mathrm{ml}$ may be sufficient for the physiological requirements of pregnancy [124]. On the other hand, negative dependence between vitamin D and GDM was found in the review of Spanish studies [103]. There are also several different studies in which vitamin $D$ failed to prevent the development of GDM in pregnant women $[72,125,126]$, such as the study by Makgoba et al., which found no association between maternal first-trimester circulation of 25(OH)D and development of GDM [127].

In our opinion, the lack of repeatability of the results encourages further research in this field. Large prospective studies to finally evaluate the role of vitamin D in GDM are a must. It is important to select groups appropriately. Ethnicity, body mass index, and accompanying complaints can modify the results and lead to various conclusions. The moment of vitamin $D$ level determination is crucial, which is why not all studies are comparable.

What about vitamin D supplementation in GDM? There have been various trials investigating vitamin D supplementation in the prevention or reduction of the risk of developing GDM. According to Robinson, vitamin D supplementation might be a low cost nutritional intervention to reduce GDM [128]. The study by Soheilykhah et al. showed that supplementation with high doses of vitamin D in pregnant women significantly improved insulin resistance, which is why they concluded that low serum levels of $25(\mathrm{OH}) \mathrm{D}$ were related to insulin resistance during pregnancy [129]. Zhang et al. found that vitamin D supplementation during pregnancy reduces the risk of GDM occurrence [123]. In an interesting study by Yap et al., two groups of vitamin $D$ deficient women were supplemented with different doses of vitamin D - no differences in pregnancy outcomes were found [130]. There are also current meta-analyses that have presented the same incidence of GDM development in groups with and without vitamin D supplementation $[13,131]$. In their review, Agarwal et al. concluded that vitamin D supplementation in the prevention of GDM is irrelevant [66].

\section{Low birth weight}

Fetal growth restriction is a major problem in current perinatology. Intrauterine growth restriction, which may account for being small for gestational age (SGA) or low birth weight, greatly increases the risk of negative perinatal outcomes and the probability of metabolic diseases later in 
life $[132,133]$. Vitamin D, as a pleiotropic agent, regulates fetal growth and metabolism starting in early embryogenesis [54]. Vitamin D status during pregnancy plays a major role in musculoskeletal development, tooth enamel formation, fetal growth, and neurological development [134]. One of the most important clues may be the optimal fetal bone growth when maternal vitamin D serum levels are sufficient [135]. The study by Puthuraya et al. investigated whether vitamin D is associated with placental inflammation in very low birth weight fetuses, but found no correlation [136]. In a recent study by Workalemahu et al., common placental genetic variations were investigated to identify associations between the influence of vitamin $\mathrm{D}$ and birthweight. Many associations in polymorphisms were found [137]. In our opinion, this is the starting point for larger studies that will provide some new information as to why some fetuses react to specific vitamin D levels, while others do not [137]. While in the above-mentioned pathologies, the results were very often contradictory, here the results were more similar. Bodnar et al. presented data indicating that maternal serum 25-hydroxyvitamin D levels were correlated with the birth of SGA neonates in white women [138]. In a study by Chen et al. enrolling almost 3700 pregnant Chinese women, maternal vitamin $D$ deficiency during pregnancy was found to elevate the risk of low birth weight [133]. A multi-ethnic study by Leffelaar et al. concluded that women with low vitamin $D$ levels had more than two times higher risk of finishing a pregnancy with an SGA neonate [139]. In the large study by Miliku et al. performed on almost 7100 pregnant women, low maternal $25(\mathrm{OH}) \mathrm{D}$ serum concentrations were associated with intrauterine growth restriction and increased risk of small size for gestational age at birth [140]. In a study by Gernand et al., maternal vitamin D status was found to be related to the risk of SGA in white and non-obese women. This correlation was not confirmed in black and obese women [141]. According to data gained from several medical centers located in the USA, a maternal $25(\mathrm{OH}) \mathrm{D}$ serum level of at least $15 \mathrm{ng} / \mathrm{ml}$ during the first trimester of pregnancy was associated with a two times lower risk of giving birth to an SGA neonate [142]. In the study by Burris et al. second trimester $25(\mathrm{OH}) \mathrm{D}$ serum levels lower than $10 \mathrm{ng} / \mathrm{ml}$ were associated with higher odds of SGA in both black (higher risk) and white populations [143] In an old, but very interesting, study by Marya et al., the highest birthweights were obtained in mothers who received high vitamin $D$ doses during the third trimester of pregnancy [144]. A systematic review and meta-analysis by Perez-Lopez et al. pointed out that vitamin D supplementation during pregnancy has been associated with higher birthweight [131]. These data were also confirmed in a later meta-analysis of Spanish studies [103]. $A$ very recent well-performed meta-analysis by $\mathrm{Bi}$ et al. based on 24 clinical trials found that vitamin D supplementation during pregnancy reduces the risk of an SGA neonate. The authors concluded that vitamin D supplementation with doses of $2000 \mathrm{IU} /$ day (higher doses do not improve the outcomes) during pregnancy significantly reduces the risk of fetal or neonatal mortality [145]. Morley et al. reported that low vitamin D levels in late pregnancy were correlated with reduced fetal long bone growth [146]. On the other hand, Eggemoen et al. recently published their study in which they found no independent relationship between maternal vitamin D serum status and neonatal anthropometric measures [147].

In our opinion, the relationship between maternal vitamin D status at different gestational stages and the risk of low birth weight is backed by considerable evidence. In the above-mentioned literature we observed a positive relationship between maternal 25(OH)D serum levels during pregnancy and birth weight in their offspring. More research is still needed to determine the exact influences and groups of patients in whom the intervention would be necessary.

\section{Preterm birth}

Preterm birth is a situation when a neonate is born before 37 weeks of pregnancy. The causes of preterm birth are still under investigation. The risk factors vary, from diabetes, hypertension, multiple pregnancies, obesity, underweight, or vaginal infections to alcoholism, smoking, and stress [148]. After preterm birth, infants are at higher risk for morbidities including cerebral palsy, bronchopulmonary dysplasia, and impairment of senses [149, 150]. The rapid rise of maternal corticotropin-releasing hormone $(\mathrm{CRH})$ is believed to be a trigger for preterm birth [151, 152]. The exact functions of vitamin $D$ in preterm birth are still unknown, but there are in vitro studies revealing it may have immunomodulatory and anti-inflammatory effects in preterm birth pathophysiology [150, 153]. Vitamin $D$ is a factor that reduces the macrophage-mediated inflammatory processes. In the study by Mohamed et al., women who experienced preterm birth showed high serum levels of maternal CRH and low vitamin D status [152]. This study has been described as preliminary, but further research might confirm that vitamin D regulates $\mathrm{CRH}$ through effects on inflammatory mechanisms [152]. The $\mathrm{CRH}$ is believed to be one of the main generators of parturition [152, 154]. Peripheral inflammation stimulates the central release of $\mathrm{CRH}$. This stimulation ends with an increased level of glucocorticoids that will induce placental $\mathrm{CRH}$ production [155]. Vitamin D might affect the 
occurrence and intensity of inflammation in several molecular pathways - in many opinions, this is a point where vitamin $D$ status might be crucial $[152,156]$. According to several studies, vitamin D plays an important role in immunomodulation and cytokine balancing. Vitamin D was shown to raise the production of anti-inflammatory cytokines (IL-4) with an additional effect on reducing the ones responsible for inflammation triggering (IL-2, IL-6, IL-10, TNF- $\alpha$ ) [157]. Vitamin D deficiency is one of the processes responsible for upregulation of monocyte toll-like receptors, which are known as pro-inflammatory cells [158]. Vitamin D inhibits cox-2 expression, due to the influence on the Akt/NF- $\mathrm{kB}$ signaling pathway [159]. According to Zhang et al. this vitamin inhibits macrophage pro-inflammatory cytokine production by the effect on mitogen-activated protein kinase phosphatase 1 [160]. A recent study by Javorski et al. found an interesting association between Fokl and $\mathrm{Cdx}-2$ single nucleotide polymorphisms within the vitamin $D$ receptor gene, suggesting their involvement in the occurrence of spontaneous preterm birth. In groups with this symptom the T allele for rs2228570 and A allele for rs11568820 are more frequent [161].

The Canadian study about maternal vitamin D deficiency in early pregnancy revealed that it is associated with an increased risk of preterm birth in the future [162]. According to Baczyńska-Strzecha and Kalinka vitamin D serum levels lower than $10 \mathrm{ng} / \mathrm{ml}$ may be an important factor increasing the risk of preterm birth in the Polish population [163]. There are several other new studies about the relationship between vitamin $D$ status and the risk of preterm birth. The results of these studies are very encouraging and suggest that optimal serum levels of vitamin $D$ significantly reduce the risk of preterm birth in different populations [126, 164-168]. In a study by Wagner et al. 25(OH)D serum levels higher than $40 \mathrm{ng} / \mathrm{ml}$ in the third trimester were associated with almost $50 \%$ reduction in preterm birth numbers [167]. According to Bodnar et al., the risk of preterm birth is highest when 25(OH)D serum levels are lower than $20 \mathrm{ng} /$ $\mathrm{ml}$, and it gets lower when serum levels are more than $35 \mathrm{ng} / \mathrm{ml}$ [169]. A very interesting study about twin pregnancies and the risk of preterm birth between women with sufficient and insufficient vitamin D status suggested an almost $60 \%$ reduction of risk in patients who had a $25(\mathrm{OH}) \mathrm{D}$ serum level of more than $30 \mathrm{ng} / \mathrm{ml}$ [170]. In a recent study by McDonnell et al., patients were administered vitamin $D$ supplements to achieve a $25(\mathrm{OH}) \mathrm{D}$ serum level of more than $40 \mathrm{ng} / \mathrm{ml}$. The results were more than encouraging, as women with proper vitamin D levels had an almost $60 \%$ lower risk of preterm birth [63]. Maternal 25(OH)D concentrations higher than $40 \mathrm{ng} / \mathrm{ml}$ were associ- ated with a substantial reduction in preterm birth risk in a large, diverse population of women [63]. On the other hand, a meta-analysis of Spanish studies failed to prove the effect of higher $25(\mathrm{OH}) \mathrm{D}$ serum levels on pregnancy outcomes [103].

In our opinion, there is still a place for a RCTs regarding vitamin $\mathrm{D}$ status and supplementation in the reduction of preterm births because there are still no RCTs with preterm birth as a major outcome. The available data show that sufficient vitamin D status reduces the risk of preterm birth.

\section{Screening and supplementation}

There are several questions about the role of vitamin $D$ in perinatology at the beginning of the year 2018. What can be done to improve adverse perinatal outcomes using vitamin D? Do we need to screen for vitamin D deficiency? If yes, then who should be screened? What kind of supplementation should be chosen?

According to the above-mentioned data, some groups (e.g. overweight patients) are at increased risk for adverse perinatal outcomes due to vitamin D deficiency. In those groups, measurement of vitamin D status appears to be applicable with a good effect. There are still no good data that support routine screening for vitamin D deficiency in pregnancy. The testing is still expensive, in comparison with other blood examinations performed during pregnancy. The problem is the cost-effectiveness in universal application [171], but in 2013 a group of experts identified vitamin D as a critical intervention that might have a potential impact on reducing the risk of adverse perinatal outcomes worldwide [172]. Vitamin D supplementation in pregnancy remains a possible intervention that may improve pregnancy outcomes by preventing the occurrence of preeclampsia, GDM, low birth weight, and preterm birth [102, 173]. In an outstanding review from 2014, Wei supported this thesis [49]. A very recent study by Rostami et al., who screened and supplemented vitamin D in pregnant women, found that this prenatal activity is an effective approach in detecting deficient women, improving vitamin $\mathrm{D}$ levels and decreasing adverse pregnancy outcomes (preeclampsia, GDM, and preterm delivery were decreased by $60 \%, 50 \%$ and $40 \%$ in selected populations). What is more, a monthly 50,000 IU injectible maintenance therapy contributed the most to achieving vitamin D sufficiency at delivery [174].

There are several guidelines about vitamin $D$ supplementation in pregnancy [175-178]. As can be seen in the study by Ceccaldi et al., some guideline-based supplementation doses may be insufficient, because they fail to obtain an optimal status in infants. As a result, some authors suggest a new recommendation with higher 
vitamin D doses for all pregnant women [179]. Some researchers are using higher supplementation doses than proposed by guidelines, and are obtaining exceptionally good results $[54,57$, 180]. Evidence supports optimal vitamin D serum levels and supplementation in improving fetal growth and neonatal outcomes [27, 49, 59, 145, $174,181,182]$. As stated by Curtis et al., evidence tends towards better vitamin D serum levels and supplementation being of overall benefit, but some of the data do not reach statistical significance [183].

The main clinical challenge is to find the optimal vitamin D status and the most cost-effective dose that would prevent adverse outcomes [178]. Top experts on vitamin D suggest that the optimal level of vitamin $D$ should be higher than $30 \mathrm{ng} /$ $\mathrm{ml}$ (preferred 40-60 ng/ml) [4, 177]. Very recent Polish guidelines by Rusińska et al. advise maintaining optimal concentrations within the range of $30-50 \mathrm{ng} / \mathrm{ml}$ when pregnancy is confirmed. The supplementation should be carried out under the control of 25(OH)D serum levels [178]. Based on cited data and our experience, we fully support this position, because at these levels we are obtaining the best obstetric outcomes. On the other hand, when summarizing the total costs and several inconveniences of vitamin D status population screening, why not just recommend higher doses of vitamin D (e.g. 4000 units/day) for all pregnant women? In the opinion of several experts, a quick review of risk factors and the recommendation proposed is simple and effective. High doses of vitamin D and 25(OH)D level examination after 4 to 8 weeks could be a convenient method due to the lag between supplementation start and the plateau of appropriate vitamin D serum levels [184, 185]. The supplementation strategy is also of high importance, as there are differences in low-dose daily doses and weekly or monthly loading dose effects in different groups [186].

Vitamin $D$ is an inexpensive and safe drug with a low risk of toxicity. It can be safely supplemented in pregnancy, even in high doses. Due to these facts, vitamin D supplementation in pregnant women should be recommended to achieve appropriate serum levels and reduce the risk of adverse outcomes [30]. Especially this screening should be recommended in pregnant women with high risk of vitamin D deficiency [187]. Rather than using a universal supplementation dose of vitamin $D$, a better solution seems to be first trimester screening of vitamin D status using $25(\mathrm{OH}) \mathrm{D}$ [174] and individual dosage adjustment to compensate for potential deficits [178]. In our opinion, such a policy can bring surprisingly good results in a short time, but the problem is the overall cost of this procedure.
The emphasis should be placed on gynecologists and obstetricians to remember the role of vitamin $D$ in pregnancy. At this point, the main role is played by national obstetrical societies that should keep up with current knowledge and make up-to-date guidelines about the role of vitamin D supplementation and its role in perinatology. It is also the role of experts and societies to collect opinions of other colleagues on optimal recommendations. In a study by Mohamed et al., a large group of obstetricians was more likely to screen routinely. They also believed that vitamin D supplementation was beneficial for pregnant women [29]. A majority of those obstetricians indicated that vitamin $D$ insufficiency in pregnant women was a problem in their practice [29].

We still should not forget about interactions between vitamin $D$, vitamin $D$ receptors, genetics, and other factors $[109,161]$. The effect of vitamin D on genomics has not been evaluated, and that is why we still need to be careful and do more research in this field to gain new knowledge [57].

\section{Conclusions}

Vitamin D deficiency is an increasing problem worldwide. The evidence from this review suggests associations between low levels of maternal vitamin $D$ and a higher risk of selected obstetrical complications. Vitamin $D$ has been found to be related to various adverse perinatal outcomes, such as preeclampsia, GDM, low birth weight, and preterm birth (Figure 1).

A large body of mutually exclusive research has caused a huge problem in choosing the right course for this vitamin in pregnancy. The studies are ongoing and we will gain more data in the near future. To determine the real benefits of vitamin D supplementation in pregnancy, we need double-blind, high-quality RCTs on large or very large groups. This could show the real effect of vitamin D supplementation on adverse pregnancy outcomes and provide substantial information for

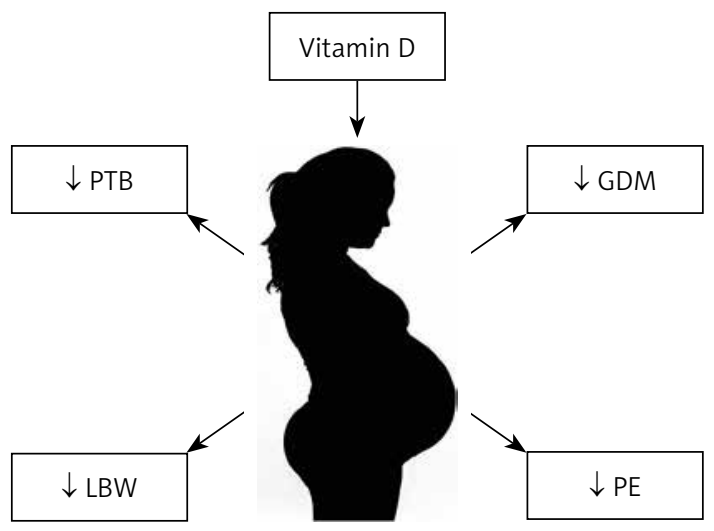

Figure 1. Vitamin D reduces the risk of four major severe pregnancy outcomes 
public health. Available data are often inconclusive due to suboptimal clinical phenotyping, misleading characteristics and large heterogeneity [100].

In our opinion, vitamin D supplementation in pregnant women is considerable, but more highquality data are still necessary. According to the systematic review by Roth et al., current evidence seems insufficient to guide new clinical recommendations [188]. The problem that remains is how to achieve an optimal 25(OH)D level and a dose providing optimal supplementation. Perhaps the solution is routine screening and individual vitamin $D$ dose selection. Only very high-quality randomized placebo-controlled trials will confirm the potential efficacy and safety of vitamin D supplementation in pregnancy [183].

\section{Conflict of interest}

The authors declare no conflict of interest.

\section{References}

1. Weinert LS, Silveiro SP. Maternal-fetal impact of vitamin D deficiency: a critical review. Matern Child Health J 2015; 19: 94-101.

2. Holick MF. Vitamin D: a millenium perspective. J Cell Biochem 2003; 88: 296-307.

3. Holick MF. Vitamin D deficiency. N Engl J Med 2007; 357: 266-81.

4. Holick MF. The vitamin D deficiency pandemic: approaches for diagnosis, treatment and prevention. Rev Endocr Metab Disord 2017; 18: 153-65.

5. Holick MF. Vitamin D and bone health. J Nutr 1996; 126 (4 Suppl): 1159S-64S.

6. Anderson PH. Vitamin D activity and metabolism in bone. Curr Osteoporos Rep 2017; 15: 443-9.

7. Taylor SN, Wahlquist A, Wagner CL, Ramakrishnan V, Ebeling $M$, Hollis BW. Functional indicators of vitamin $D$ adequacy for very low birth weight infants. J Perinatol 2018; 38: 550-6.

8. Joergensen JS, Lamont RF, Torloni MR. Vitamin D and gestational diabetes: an update. Curr Opin Clin Nutr Metab Care 2014; 17: 360-7.

9. Haussler MR, Jurutka PW, Mizwicki M, Norman AW. Vitamin D receptor (VDR)-mediated actions of $1 \mathrm{al}$ pha,25(OH)(2)vitamin $\mathrm{D}(3)$ : genomic and non-genomic mechanisms. Best Pract Res Clin Endocrinol Metab 2011; 25: 543-59.

10. Holick MF. Too little vitamin D in premenopausal women: why should we care? Am I Clin Nutr 2002; 76: 3-4.

11. Holick MF. Sunlight and vitamin D for bone health and prevention of autoimmune diseases, cancers, and cardiovascular disease. Am J Clin Nutr 2004; 80 (6 Suppl): 1678S-88S.

12. Deluca HF. History of the discovery of vitamin D and its active metabolites. Bonekey Rep 2014; 3: 479.

13. De-Regil LM, Palacios C, Lombardo LK, Pena-Rosas JP. Vitamin D supplementation for women during pregnancy. Cochrane Database Syst Rev 2016; 1: CD008873.

14. Anagnostis P, Karras S, Goulis DG. Vitamin D in human reproduction: a narrative review. Int J Clin Pract 2013; 67: 225-35.

15. Webb AR. Who, what, where and when-influences on cutaneous vitamin D synthesis. Prog Biophys Mol Biol 2006; 92: 17-25.
16. Christakos S, Dhawan P, Benn B, et al. Vitamin D: molecular mechanism of action. Ann N Y Acad Sci 2007; 1116: 340-8.

17. Seamans KM, Cashman KD. Existing and potentially novel functional markers of vitamin D status: a systematic review. Am J Clin Nutr 2009; 89: 1997S-2008S.

18. Holick MF, Binkley NC, Bischoff-Ferrari HA, et al. Evaluation, treatment, and prevention of vitamin D deficiency: an Endocrine Society clinical practice guideline. J Clin Endocrinol Metab 2011; 96: 1911-30.

19. Ensrud KE, Crandall CJ. Osteoporosis. Ann Intern Med 2017; 167: ITC17-32.

20. Dawodu A, Wagner CL. Mother-child vitamin D deficiency: an international perspective. Arch Dis Child 2007; 92: 737-40.

21. Souberbielle JC, Massart C, Brailly-Tabard S, Cavalier E, Chanson P. Prevalence and determinants of vitamin D deficiency in healthy French adults: the VARIETE study. Endocrine 2016; 53: 543-50.

22. Gustafsson MK, Romundstad PR, Stafne SN, et al. Alterations in the vitamin $D$ endocrine system during pregnancy: a longitudinal study of 855 healthy Norwegian women. PLOS One 2018; 13: e0195041.

23. Holick MF, Chen TC. Vitamin D deficiency: a worldwide problem with health consequences. Am J Clin Nutr 2008; 87: 1080S-6S.

24. Yao S, Hong CC, Bandera EV, et al. Demographic, lifestyle, and genetic determinants of circulating concentrations of 25-hydroxyvitamin D and vitamin D-binding protein in African American and European American women. Am J Clin Nutr 2017; 105: 1362-71.

25. Clemens TL, Adams JS, Henderson SL, Holick MF. Increased skin pigment reduces the capacity of skin to synthesize vitamin D3. Lancet 1982; 8263: 74-60.

26. Palacios C, Gonzalez L. Is vitamin D deficiency a major global public health problem? J Steroid Biochem Mol Biol 2014; 144 Pt A: 138-45.

27. Palacios C, De-Regil LM, Lombardo LK, Pena-Rosas JP. Vitamin D supplementation during pregnancy: updated meta-analysis on maternal outcomes. J Steroid Biochem Mol Biol 2016; 164: 148-55.

28. Casey C, McGinty A, Holmes VA, et al. Maternal vitamin $D$ and markers of glycaemia during pregnancy in the Belfast Centre of the Hyperglycaemia and Adverse Pregnancy Outcome study. Diabet Med 2018; 35: 972-9.

29. Mohamed SA, Al-Hendy A, Schulkin J, Power ML. Opinions and practice of US-based obstetrician-gynecologists regarding vitamin D screening and supplementation of pregnant women. J Pregnancy 2016; 2016: 1454707.

30. van der Pligt P, Willcox J, Szymlek-Gay EA, Murray E, Worsley A, Daly RM. Associations of maternal vitamin $D$ deficiency with pregnancy and neonatal complications in developing countries: a systematic review. Nutrients 2018; 10: 640.

31. Ilincic B, Stokic E, Stosic Z, et al. Vitamin D status and circulating biomarkers of endothelial dysfunction and inflammation in non-diabetic obese individuals: a pilot study. Arch Med Sci 2017; 13: 53-60.

32. Christakos S, Dhawan P, Verstuyf A, Verlinden L, Carmeliet G. Vitamin D: metabolism, molecular mechanism of action, and pleiotropic effects. Physiol Rev 2016; 96: 365-408.

33. Dimova R, Tankova T, Chakarova N. Vitamin D in the spectrum of prediabetes and cardiovascular autonomic dysfunction. J Nutr 2017; 147: 1607-15. 
34. Ji JL, Muyayalo KP, Zhang YH, Hu XH, Liao AH. Immunological function of vitamin $\mathrm{D}$ during human pregnancy. Am J Reprod Immunol 2017; 78(2). doi: 10.1111/ aji.12716.

35. Faridi KF, Lupton JR, Martin SS, et al. Vitamin D deficiency and non-lipid biomarkers of cardiovascular risk. Arch Med Sci 2017; 13: 732-7.

36. Mazidi M, Michos ED, Banach $M$. The association of telomere length and serum 25-hydroxyvitamin D levels in US adults: the National Health and Nutrition Examination Survey. Arch Med Sci 2017; 13: 61-5.

37. Akoh CC, Pressman EK, Cooper E, Queenan RA, Pillittere J, O'Brien KO. Low vitamin D is associated with infections and proinflammatory cytokines during pregnancy. Reprod Sci 2018; 25: 414-23.

38. Yates N, Crew RC, Wyrwoll CS. Vitamin D deficiency and impaired placental function: potential regulation by glucocorticoids? Reproduction 2017; 153: R163-71.

39. Olmos-Ortiz A, Noyola-Martinez N, Barrera D, et al. IL-10 inhibits while calcitriol reestablishes placental antimicrobial peptides gene expression. J Steroid Biochem Mol Biol 2015; 148: 187-93.

40. Hong SH, Lee JE, An SM, et al. Effect of vitamin D3 on biosynthesis of estrogen in porcine granulosa cells via modulation of steroidogenic enzymes. Toxicol Res 2017; 33: 49-54

41. Dusilova-Sulkova S. Vitamin D metabolism and vitamin D traditional and nontraditional, target organs: implications for kidney patients. J Ren Care 2009; 35 Suppl 1: 39-44.

42. Rai V, Abdo J, Agrawal S, Agrawal DK. Vitamin D receptor polymorphism and cancer: an update. Anticancer Res 2017; 37: 3991-4003.

43. Ismail MM, Abdel Hamid TA, Ibrahim AA, Marzouk H. Serum adipokines and vitamin $D$ levels in patients with type 1 diabetes mellitus. Arch Med Sci 2017; 13: 738-44.

44. Giannini S, Mazzaferro S, Minisola S, De Nicola L, Rossini M, Cozzolino M. Raising awareness on the therapeutic role of cholecalciferol in CKD: a multidisciplinary-based opinion. Endocrine 2018; 59: 242-59.

45. Franasiak JM, Lara EE, Pellicer A. Vitamin D in human reproduction. Curr Opin Obstet Gynecol 2017; 29: 189-94.

46. Kim RH, Ryu BJ, Lee KM, Han JW, Lee SK. Vitamin D facilitates trophoblast invasion through induction of epithelial-mesenchymal transition. Am J Reprod Immunol 2018; 79(2). doi: 10.1111/aji.12796.

47. Brannon PM. Vitamin D and adverse pregnancy outcomes: beyond bone health and growth. Proc Nutr Soc 2012; 71: 205-12.

48. Shin JS, Choi MY, Longtine MS, Nelson DM. Vitamin D effects on pregnancy and the placenta. Placenta 2010; 31: 1027-34.

49. Wei SQ. Vitamin D and pregnancy outcomes. Curr Opin Obstet Gynecol 2014; 26: 438-47.

50. Kiely M, Hemmingway A, O'Callaghan KM. Vitamin D in pregnancy: current perspectives and future directions. Ther Adv Musculoskelet Dis 2017; 9: 145-54.

51. Lee CL, Ng BK, Wu LL, Cheah FC, Othman H, Ismail NAM. Vitamin D deficiency in pregnancy at term: risk factors and pregnancy outcomes. Horm Mol Biol Clin Investig 2017; 31 doi: 10.1515/hmbci-2017-0005.

52. Dabrowski FA, Grzechocinska B, Wielgos M. The role of vitamin D in reproductive health: a Trojan Horse or the Golden Fleece? Nutrients 2015; 7: 4139-53.

53. Baker BC, Hayes D, Jones RL. Effects of micronutrients on placental function: evidence from clinical studies to animal models. Reproduction 2018; 156: R69-82.
54. Hollis BW, Wagner CL. Vitamin D and pregnancy: skeletal effects, nonskeletal effects, and birth outcomes. Calcif Tissue Int 2013; 92: 128-39.

55. Olmos-Ortiz A, Avila E, Durand-Carbajal M, Diaz L. Regulation of calcitriol biosynthesis and activity: focus on gestational vitamin $\mathrm{D}$ deficiency and adverse pregnancy outcomes. Nutrients 2015; 7: 443-80.

56. Marshall I, Mehta R, Petrova A. Vitamin D in the maternal-fetal-neonatal interface: clinical implications and requirements for supplementation. J Matern Fetal Neonatal Med 2013; 26: 633-8.

57. Hollis BW, Wagner CL. Vitamin D supplementation during pregnancy: improvements in birth outcomes and complications through direct genomic alteration. Mol Cell Endocrinol 2017; 453: 113-30.

58. Salle BL, Delvin EE, Lapillonne A, Bishop NJ, Glorieux $\mathrm{FH}$. Perinatal metabolism of vitamin $\mathrm{D}$. Am J Clin Nutr 2000; 71 (5 Suppl): 1317S-24S.

59. Hollis BW, Johnson D, Hulsey TC, Ebeling M, Wagner CL. Vitamin D supplementation during pregnancy: double-blind, randomized clinical trial of safety and effectiveness. J Bone Miner Res 2011; 26: 2341-57.

60. Moller UK, Streym S, Mosekilde L, et al. Changes in calcitropic hormones, bone markers and insulin-like growth factor I (IGF-I) during pregnancy and postpartum: a controlled cohort study. Osteoporos Int 2013; 24: 1307-20.

61. Park H, Brannon PM, West AA, et al. Maternal vitamin D biomarkers are associated with maternal and fetal bone turnover among pregnant women consuming controlled amounts of vitamin D, calcium, and phosphorus. Bone 2017; 95: 183-91.

62. Heyden EL, Wimalawansa SJ. Vitamin D: effects on human reproduction, pregnancy, and fetal well-being. J Steroid Biochem Mol Biol 2018; 180: 41-50.

63. MCDonnell SL, Baggerly KA, Baggerly CA, et al. Maternal $25(\mathrm{OH}) \mathrm{D}$ concentrations $>/=40 \mathrm{ng} / \mathrm{mL}$ associated with $60 \%$ lower preterm birth risk among general obstetrical patients at an urban medical center. PLoS One 2017; 12: e0180483.

64. Tabesh M, Salehi-Abargouei A, Tabesh M, Esmaillzadeh A. Maternal vitamin D status and risk of pre-eclampsia: a systematic review and meta-analysis. J Clin Endocrinol Metab 2013; 98: 3165-73.

65. Aghajafari F, Nagulesapillai T, Ronksley PE, Tough SC, O’Beirne M, Rabi DM. Association between maternal serum 25-hydroxyvitamin D level and pregnancy and neonatal outcomes: systematic review and meta-analysis of observational studies. BMJ 2013; 346: f1169.

66. Agarwal S, Kovilam O, Agrawal DK. Vitamin D and its impact on maternal-fetal outcomes in pregnancy: a critical review. Crit Rev Food Sci Nutr 2017; 58: 755-69.

67. Palaniswamy S, Williams D, Jarvelin MR, Sebert S. Vitamin $D$ and the promotion of long-term metabolic health from a programming perspective. Nutr Metab Insights 2015; 8 (Suppl 1): 11-21.

68. Chi MZ, Zhu L, Zhang ZL, et al. The relationship between maternal serum vitamin $D$ levels and infant neurodevelopment and anthropometry: a prospective observational study. J Nutr Sci Vitaminol (Tokyo) 2018; 64: 161-7.

69. Parr CL, Magnus MC, Karlstad O, et al. Vitamin A and D intake in pregnancy, infant supplementation, and asthma development: the Norwegian Mother and Child Cohort. Am J Clin Nutr 2018; 107: 789-98.

70. Hyde NK, Brennan-Olsen SL, Wark JD, Hosking SM, Holloway-Kew KL, Pasco JA. Vitamin D during pregnancy and offspring body composition: a prospective cohort study. Pediatr Obes 2018; 13: 514-21. 
71. Dror DK, Allen LH. Vitamin D inadequacy in pregnancy: biology, outcomes, and interventions. Nutr Rev 2010; 68: 465-77.

72. Flood-Nichols SK, Tinnemore D, Huang RR, Napolitano PG, Ippolito DL. Vitamin D deficiency in early pregnancy. PLoS One 2015; 10: e0123763.

73. Holick MF. Vitamin D status: measurement, interpretation, and clinical application. Ann Epidemiol 2009; 19: 73-8.

74. Glendenning P. Measuring vitamin D. Aust Prescr 2015; 38: $12-5$.

75. Zerwekh JE. Blood biomarkers of vitamin D status. Am J Clin Nutr 2008; 87: 1087S-91S.

76. Grant WB, Boucher BJ, Bhattoa HP, Lahore H. Why vitamin D clinical trials should be based on 25-hydroxyvitamin D concentrations. J Steroid Biochem Mol Biol 2018; 177: 266-9.

77. Mol BWJ, Roberts CT, Thangaratinam S, Magee LA, de Groot CJM, Hofmeyr GJ. Pre-eclampsia. Lancet 2016; 387: 999-1011.

78. Jim B, Karumanchi SA. Preeclampsia: pathogenesis, prevention, and long-term complications. Semin Nephrol 2017; 37: 386-97.

79. Duley $L$. The global impact of pre-eclampsia and eclampsia. Semin Perinatol 2009; 33: 130-7.

80. Fisher SJ. Why is placentation abnormal in preeclampsia? Am J Obstet Gynecol 2015; 213 (4 Suppl): S115-22.

81. Chan SY, Susarla R, Canovas D, et al. Vitamin D promotes human extravillous trophoblast invasion in vitro. Placenta 2015; 36: 403-9.

82. Tamblyn JA, Susarla R, Jenkinson C, et al. Dysregulation of maternal and placental vitamin $D$ metabolism in preeclampsia. Placenta 2017; 50: 70-7.

83. Verburg PE, Dekker GA, Tucker G, Scheil W, Erwich J, Roberts CT. Seasonality of hypertensive disorders of pregnancy - a South Australian population study. Pregnancy Hypertens 2018; 12: 118-23.

84. Fischer D, Schroer A, Ludders D, et al. Metabolism of vitamin D3 in the placental tissue of normal and preeclampsia complicated pregnancies and premature births. Clin Exp Obstet Gynecol 2007; 34: 80-4.

85. Wei SQ, Audibert F, Luo ZC, et al. Maternal plasma 25-hydroxyvitamin D levels, angiogenic factors, and preeclampsia. Am J Obstet Gynecol 2013; 208: 390 e1-6.

86. Wei SQ, Bilodeu JF, Julien P, et al. Association of maternal vitamin D status and oxidative stress during pregnancy and risk of preeclampsia. Am J Obstet Gynecol 2014; 210: S169-70.

87. Naghshineh E, Sheikhaliyan S. Effect of vitamin D supplementation in the reduce risk of preeclampsia in nulliparous women. Adv Biomed Res 2016; 5: 7.

88. Schulz EV, Cruze L, Wei W, Gehris J, Wagner CL. Maternal vitamin D sufficiency and reduced placental gene expression in angiogenic biomarkers related to comorbidities of pregnancy. J Steroid Biochem Mol Biol 2017; 173: $273-9$

89. Jia X, Gu Y, Groome LJ, et al. 1,25(OH)2D3 induces placental vascular smooth muscle cell relaxation by phosphorylation of myosin phosphatase target subunit 1ser507: potential beneficial effects of vitamin $D$ on placental vasculature in humans. Biol Reprod 2016; 94: 116.

90. Tian X, Ma S, Wang Y, et al. Effects of placental ischemia are attenuated by 1,25-dihydroxyvitamin D treatment and associated with reduced apoptosis and increased autophagy. DNA Cell Biol 2016; 35: 59-70.

91. Robinson CJ, Alanis MC, Wagner CL, Hollis BW, Johnson DD. Plasma 25-hydroxyvitamin D levels in early- onset severe preeclampsia. Am J Obstet Gynecol 2010; 203: 366 e1-6.

92. Robinson CJ, Wagner CL, Hollis BW, Baatz JE, Johnson DD. Maternal vitamin D and fetal growth in earlyonset severe preeclampsia. Am J Obstet Gynecol 2011; 204: 556 e1-4.

93. Baker AM, Haeri S, Camargo CA Jr, Espinola JA, Stuebe AM. A nested case-control study of midgestation vitamin $D$ deficiency and risk of severe preeclampsia. J Clin Endocrinol Metab 2010; 95: 5105-9.

94. Bodnar LM, Catov JM, Simhan HN, Holick MF, Powers RW, Roberts JM. Maternal vitamin D deficiency increases the risk of preeclampsia. J Clin Endocrinol Metab 2007; 92: 3517-22.

95. Bener A, Al-Hamaq AO, Saleh NM. Association between vitamin $D$ insufficiency and adverse pregnancy outcome: global comparisons. Int J Womens Health 2013; 5: 523-31.

96. Bodnar LM, Simhan HN, Catov JM, et al. Maternal vitamin D status and the risk of mild and severe preeclampsia. Epidemiology 2014; 25: 207-14.

97. Robinson CJ, Wagner CL, Hollis BW, Baatz JE, Johnson DD. Association of maternal vitamin D and placenta growth factor with the diagnosis of early onset severe preeclampsia. Am J Perinatol 2013; 30: 167-72.

98. Ringrose JS, PausJenssen AM, Wilson M, Blanco L, Ward $\mathrm{H}$, Wilson TW. Vitamin D and hypertension in pregnancy. Clin Invest Med 2011; 34: E147-54.

99. Shand AW, Nassar N, Von Dadelszen P, Innis SM, Green TJ. Maternal vitamin D status in pregnancy and adverse pregnancy outcomes in a group at high risk for pre-eclampsia. BJOG 2010; 117: 1593-8.

100. O'Callaghan KM, Kiely M. Systematic review of vitamin $D$ and hypertensive disorders of pregnancy. Nutrients 2018; 10: 294.

101. Serrano NC, Guio E, Quintero-Lesmes DC, et al. Vitamin D deficiency and pre-eclampsia in Colombia: PREVitD study. Pregnancy Hypertens 2018; 14: 240-4.

102. Akbari S, Khodadadi B, Ahmadi SAY, Abbaszadeh S, Shahsavar F. Association of vitamin D level and vitamin D deficiency with risk of preeclampsia: a systematic review and updated meta-analysis. Taiwan J Obstet Gynecol 2018; 57: 241-7.

103. Martinez-Dominguez SJ, Tajada M, Chedraui P, PerezLopez FR. Systematic review and meta-analysis of Spanish studies regarding the association between maternal 25-hydroxyvitamin D levels and perinatal outcomes. Gynecol Endocrinol 2018; 34: 987-94.

104. Stougaard M, Damm P, Frederiksen P, Jacobsen R, Heitmann BL. Extra vitamin D from fortification and the risk of preeclampsia: the D-tect Study. PLoS One 2018; 13: e0191288.

105. Stougaard M, Damm P, Frederiksen P, Jacobsen R, Heitmann BL. Exposure to vitamin D from fortified margarine during fetal life and later risk of pre-eclampsia: the D-tect Study. Public Health Nutr 2018; 21: 721-31.

106. Haugen M, Brantsaeter AL, Trogstad L, et al. Vitamin D supplementation and reduced risk of preeclampsia in nulliparous women. Epidemiology 2009; 20: 720-6.

107. Purswani JM, Gala P, Dwarkanath P, Larkin HM, Kurpad A, Mehta S. The role of vitamin D in pre-eclampsia: a systematic review. BMC Pregnancy Childbirth 2017; 17: 231.

108. Standards of Medical Care in Diabetes-2016: Summary of Revisions. Diabetes Care 2016; 39 Suppl 1: S4-5. 
109. Triunfo S, Lanzone A, Lindqvist PG. Low maternal circulating levels of vitamin $D$ as potential determinant in the development of gestational diabetes mellitus. J Endocrinol Invest 2017; 40: 1049-59.

110. Forouhi NG, Luan J, Cooper A, Boucher BJ, Wareham NJ. Baseline serum 25-hydroxy vitamin D is predictive of future glycemic status and insulin resistance: the Medical Research Council Ely Prospective Study 1990-2000. Diabetes 2008; 57: 2619-25.

111. Mitri J, Pittas AG. Vitamin D and diabetes. Endocrinol Metab Clin North Am 2014; 43: 205-32.

112. Burris HH, Camargo CA Jr. Vitamin D and gestational diabetes mellitus. Curr Diab Rep 2014; 14: 451.

113. Akbari M, Mosazadeh M, Lankarani KB, et al. The effects of vitamin D supplementation on glucose metabolism and lipid profiles in patients with gestational diabetes: a systematic review and meta-analysis of randomized controlled trials. Horm Metab Res 2017; 49: 647-53.

114. Maktabi M, Chamani M, Asemi Z. The effects of vitamin D supplementation on metabolic status of patients with polycystic ovary syndrome: a randomized, double-blind, placebo-controlled trial. Horm Metab Res 2017; 49: 493-8.

115. Zhang C, Qiu C, Hu FB, et al. Maternal plasma 25-hydroxyvitamin $D$ concentrations and the risk for gestational diabetes mellitus. PLoS One 2008; 3: e3753.

116. Maghbooli Z, Hossein-Nezhad A, Karimi F, Shafaei AR, Larijani B. Correlation between vitamin D3 deficiency and insulin resistance in pregnancy. Diabetes Metab Res Rev 2008; 24: 27-32.

117. Lacroix M, Battista MC, Doyon M, et al. Lower vitamin D levels at first trimester are associated with higher risk of developing gestational diabetes mellitus. Acta Diabetol 2014; 51: 609-16.

118. McManus R, Summers K, de Vrijer B, Cohen N, Thompson A, Giroux I. Maternal, umbilical arterial and umbilical venous 25-hydroxyvitamin $\mathrm{D}$ and adipocytokine concentrations in pregnancies with and without gestational diabetes. Clin Endocrinol (Oxf) 2014; 80: 635-41.

119. Al-Ajlan A, Al-Musharaf S, Fouda MA, et al. Lower vitamin D levels in Saudi pregnant women are associated with higher risk of developing GDM. BMC Pregnancy Childbirth 2018; 18: 86.

120. Wei SQ, Qi HP, Luo ZC, Fraser WD. Maternal vitamin D status and adverse pregnancy outcomes: a systematic review and meta-analysis. J Matern Fetal Neonatal Med 2013; 26: 889-99.

121. Amraei M, Mohamadpour S, Sayehmiri K, Mousavi SF, Shirzadpour E, Moayeri A. Effects of vitamin D deficiency on incidence risk of gestational diabetes mellitus: a systematic review and meta-analysis. Front Endocrinol (Lausanne) 2018; 9: 7.

122. Hu L, Zhang Y, Wang X, et al. Maternal vitamin D status and risk of gestational diabetes: a meta-analysis. Cell Physiol Biochem 2018; 45: 291-300.

123. Zhang Y, Gong Y, Xue H, Xiong J, Cheng G. Vitamin D and gestational diabetes mellitus: a systematic review based on data free of Hawthorne effect. BJOG 2018; 125: 784-93.

124. Hauta-Alus HH, Viljakainen HT, Holmlund-Suila EM, et al. Maternal vitamin D status, gestational diabetes and infant birth size. BMC Pregnancy Childbirth 2017; 17: 420 .

125. Loy SL, Lek N, Yap F, et al. Association of maternal vitamin D status with glucose tolerance and caesarean section in a multi-ethnic Asian cohort: the growing up in Singapore towards healthy outcomes study. PLoS One 2015; 10: e0142239.

126. Schneuer FJ, Roberts CL, Guilbert C, et al. Effects of maternal serum 25-hydroxyvitamin D concentrations in the first trimester on subsequent pregnancy outcomes in an Australian population. Am J Clin Nutr 2014; 99 : 287-95.

127. Makgoba M, Nelson SM, Savvidou M, Messow CM, Nicolaides K, Sattar N. First-trimester circulating 25-hydroxyvitamin $D$ levels and development of gestational diabetes mellitus. Diabetes Care 2011; 34: 1091-3.

128. Robinson CJ. Vitamin D: a possible intervention for preventing gestational diabetes? BJOG 2018; 125: 794.

129. Soheilykhah S, Mojibian M, Moghadam MJ, Shojaoddiny-Ardekani A. The effect of different doses of vitamin D supplementation on insulin resistance during pregnancy. Gynecol Endocrinol 2013; 29: 396-9.

130. Yap C, Cheung NW, Gunton JE, et al. Vitamin D supplementation and the effects on glucose metabolism during pregnancy: a randomized controlled trial. Diabetes Care 2014; 37: 1837-44.

131. Perez-Lopez FR, Pasupuleti V, Mezones-Holguin E, et al. Effect of vitamin D supplementation during pregnancy on maternal and neonatal outcomes: a systematic review and meta-analysis of randomized controlled trials. Fertil Steril 2015; 103: 1278-88 e4.

132. Bukowski R, Hansen NI, Willinger M, et al. Fetal growth and risk of stillbirth: a population-based case-control study. PLoS Med 2014; 11: e1001633.

133. Chen YH, Fu L, Hao JH, et al. Maternal vitamin D deficiency during pregnancy elevates the risks of small for gestational age and low birth weight infants in Chinese population. J Clin Endocrinol Metab 2015; 100: 1912-9.

134. Wagner CL, Taylor SN, Johnson DD, Hollis BW. The role of vitamin $\mathrm{D}$ in pregnancy and lactation: emerging concepts. Womens Health (Lond) 2012; 8: 323-40.

135. Specker BL. Does vitamin D during pregnancy impact offspring growth and bone? Proc Nutr Soc 2012; 71: 3845.

136. Puthuraya S, Karnati S, Kazzi SNJ, Qureshi F, Jacques SM, Thomas R. Does vitamin D deficiency affect placental inflammation or infections among very low birth weight infants? J Matern Fetal Neonatal Med 2018; 31: 1906-12.

137. Workalemahu T, Badon SE, Dishi-Galitzky M, et al. Placental genetic variations in vitamin D metabolism and birthweight. Placenta 2017; 50: 78-83.

138. Bodnar LM, Catov JM, Zmuda JM, et al. Maternal serum 25-hydroxyvitamin D concentrations are associated with small-for-gestational age births in white women. J Nutr 2010; 140: 999-1006.

139. Leffelaar ER, Vrijkotte TG, van Eijsden M. Maternal early pregnancy vitamin $D$ status in relation to fetal and neonatal growth: results of the multi-ethnic Amsterdam Born Children and their Development cohort. $\mathrm{Br}$ J Nutr 2010; 104: 108-17.

140. Miliku K, Vinkhuyzen A, Blanken LM, et al. Maternal vitamin D concentrations during pregnancy, fetal growth patterns, and risks of adverse birth outcomes. Am J Clin Nutr 2016; 103: 1514-22.

141. Gernand AD, Simhan HN, Caritis S, Bodnar LM. Maternal vitamin D status and small-for-gestational-age offspring in women at high risk for preeclampsia. Obstet Gynecol 2014; 123: 40-8.

142. Gernand AD, Simhan HN, Klebanoff MA, Bodnar LM. Maternal serum 25-hydroxyvitamin D and measures of 
newborn and placental weight in a U.S. multicenter cohort study. J Clin Endocrinol Metab 2013; 98: 398-404.

143. Burris HH, Rifas-Shiman SL, Camargo CA Jr, et al. Plasma 25-hydroxyvitamin D during pregnancy and small-for-gestational age in black and white infants. Ann Epidemiol 2012; 22: 581-6.

144. Marya RK, Rathee S, Manrow M. Effect of calcium and vitamin D supplementation on toxaemia of pregnancy. Gynecol Obstet Invest 1987; 24: 38-42.

145. Bi WG, Nuyt AM, Weiler H, Leduc L, Santamaria C, Wei SQ. Association between vitamin D supplementation during pregnancy and offspring growth, morbidity, and mortality: a systematic review and meta-analysis. JAMA Pediatr 2018; 172: 635-45.

146. Morley R, Carlin JB, Pasco JA, Wark JD. Maternal 25-hydroxyvitamin $D$ and parathyroid hormone concentrations and offspring birth size. J Clin Endocrinol Metab 2006; 91: 906-12.

147. Eggemoen AR, Jenum AK, Mdala I, Knutsen KV, Lagerlov P, Sletner L. Vitamin D levels during pregnancy and associations with birth weight and body composition of the newborn: a longitudinal multiethnic populationbased study. Br J Nutr 2017; 117: 985-93.

148. Lockwood CJ. Risk factors for preterm birth and new approaches to its early diagnosis. J Perinat Med 2015; 43: 499-501.

149. Cooper NA, Moores R, East London Preterm Prevention $C$. A review of the literature regarding nutritional supplements and their effect on vaginal flora and preterm birth. Curr Opin Obstet Gynecol 2014; 26: 487-92.

150. Mousa A, Abell S, Scragg R, de Courten B. Vitamin D in reproductive health and pregnancy. Semin Reprod Med 2016; 34: e1-13.

151. Leung TN, Chung TK, Madsen G, Lam PK, Sahota D, Smith R. Rate of rise in maternal plasma corticotrophin-releasing hormone and its relation to gestational length. BJOG 2001; 108: 527-32.

152. Mohamed SA, El Andaloussi A, Al-Hendy A, et al. Vitamin $D$ and corticotropin-releasing hormone in term and preterm birth: potential contributions to preterm labor and birth outcome. J Matern Fetal Neonatal Med 2018; 31: 2911-7.

153. Bodnar LM, Krohn MA, Simhan HN. Maternal vitamin D deficiency is associated with bacterial vaginosis in the first trimester of pregnancy. J Nutr 2009; 139: 1157-61.

154. McLean M, Bisits A, Davies J, Woods R, Lowry P, Smith R. A placental clock controlling the length of human pregnancy. Nat Med 1995; 1: 460-3.

155. Robinson BG, Emanuel RL, Frim DM, Majzoub JA. Glucocorticoid stimulates expression of corticotropin-releasing hormone gene in human placenta. Proc Natl Acad Sci USA 1988; 85: 5244-8.

156. Wang B, Parobchak N, Rosen T. RelB/NF-kappaB2 regulates corticotropin-releasing hormone in the human placenta. Mol Endocrinol 2012; 26: 1356-69.

157. Azizieh F, Alyahya KO, Raghupathy R. Association between levels of vitamin D and inflammatory markers in healthy women. J Inflamm Res 2016; 9: 51-7.

158. Sadeghi K, Wessner B, Laggner U, et al. Vitamin D3 down-regulates monocyte TLR expression and triggers hyporesponsiveness to pathogen-associated molecular patterns. Eur J Immunol 2006; 36: 361-70.

159. Wang Q, He Y, Shen Y, et al. Vitamin D inhibits COX-2 expression and inflammatory response by targeting thioesterase superfamily member 4. J Biol Chem 2014; 289: 11681-94

160. Zhang Y, Leung DY, Richers BN, et al. Vitamin D inhibits monocyte/macrophage proinflammatory cytokine pro- duction by targeting MAPK phosphatase-1. J Immunol 2012; 188: 2127-35

161. Javorski N, Lima CAD, Silva LVC, Crovella S, de Azevedo Silva J. Vitamin D receptor (VDR) polymorphisms are associated to spontaneous preterm birth and maternal aspects. Gene 2018; 642: 58-63.

162. Tabatabaei N, Auger N, Herba CM, et al. Maternal vitamin D insufficiency early in pregnancy is associated with increased risk of preterm birth in ethnic minority women in Canada. J Nutr 2017; 147: 1145-51.

163. Baczynska-Strzecha M, Kalinka J. Assessment of correlation between vitamin $D$ level and prevalence of preterm births in the population of pregnant women in Poland. Int J Occup Med Environ Health 2017; 30: 933-41.

164. Zhou J, Su L, Liu M, et al. Associations between 25-hydroxyvitamin D levels and pregnancy outcomes: a prospective observational study in southern China. Eur J Clin Nutr 2014; 68: 925-30.

165. Bodnar LM, Klebanoff MA, Gernand AD, et al. Maternal vitamin $D$ status and spontaneous preterm birth by placental histology in the US Collaborative Perinatal Project. Am J Epidemiol 2014; 179: 168-76.

166. Thota C, Menon R, Fortunato SJ, Brou L, Lee JE, Al-Hendy A. 1,25-Dihydroxyvitamin D deficiency is associated with preterm birth in African American and Caucasian women. Reprod Sci 2014; 21: 244-50.

167. Wagner CL, Baggerly C, McDonnell SL, et al. Post-hoc comparison of vitamin $D$ status at three timepoints during pregnancy demonstrates lower risk of preterm birth with higher vitamin D closer to delivery. J Steroid Biochem Mol Biol 2015; 148: 256-60.

168. Sablok A, Batra A, Thariani K, et al. Supplementation of vitamin $D$ in pregnancy and its correlation with feto-maternal outcome. Clin Endocrinol (Oxf) 2015; 83: 536-41.

169. Bodnar LM, Platt RW, Simhan HN. Early-pregnancy vitamin D deficiency and risk of preterm birth subtypes. Obstet Gynecol 2015; 125: 439-47.

170. Bodnar LM, Rouse DJ, Momirova V, et al. Maternal 25-hydroxyvitamin D and preterm birth in twin gestations. Obstet Gynecol 2013; 122: 91-8.

171. Sattar N, Welsh P, Panarelli M, Forouhi NG. Increasing requests for vitamin $D$ measurement: costly, confusing, and without credibility. Lancet 2012; 379: 95-6.

172. Bhutta ZA, Das JK, Rizyi A, et al. Evidence-based interventions for improvement of maternal and child nutrition: what can be done and at what cost? Lancet 2013; 9890: 452-77.

173. Mateussi MV, Latorraca COC, Daou JP, et al. What do Cochrane systematic reviews say about interventions for vitamin D supplementation? Sao Paulo Med J 2017; 135: 497-507.

174. Rostami M, Ramezani Tehrani F, Simbar M, et al. Effectiveness of prenatal vitamin D deficiency screening and treatment program: a stratified randomized field trial. J Clin Endocrinol Metab 2018; 103: 2936-48.

175. NICE. Antenatal care for uncomplicated pregnancies. 2017.

176. Pludowski P, Karczmarewicz E, Bayer M, et al. Practical guidelines for the supplementation of vitamin $D$ and the treatment of deficits in Central Europe - recommended vitamin D intakes in the general population and groups at risk of vitamin D deficiency. Endokrynol Pol 2013; 64: 319-27.

177. Pludowski P, Holick MF, Grant WB, et al. Vitamin D supplementation guidelines. J Steroid Biochem Mol Biol 2018; 175: 125-35. 
178. Rusińska A, Płudowski P, Walczak M, et al. Vitamin D supplementation guidelines for general population and groups at risk of vitamin D deficiency in Poland - recommendations of the Polish Society of Pediatric Endocrinology and Diabetes and the Expert Panel With Participation of National Specialist Consultants and Representatives of Scientific Societies - 2018 Update. Frontiers Endocrinol 2018; 9: 246.

179. Ceccaldi PF, Pejoan H, Breau N, et al. French prenatal vitamin D recommended supplementation: enough or not? J Gynecol Obstet Hum Reprod 2017; 46: 35-41.

180. Hossain N, Kanani FH, Ramzan S, et al. Obstetric and neonatal outcomes of maternal vitamin $\mathrm{D}$ supplementation: results of an open-label, randomized controlled trial of antenatal vitamin D supplementation in Pakistani women. J Clin Endocrinol Metab 2014; 99: 2448-55.

181. Wang Y, Li H, Zheng M, et al. Maternal vitamin D deficiency increases the risk of adverse neonatal outcomes in the Chinese population: a prospective cohort study. PLoS One 2018; 13: e0195700.

182. Kazzi SNJ, Karnati S, Puthuraya S, Thomas R. Vitamin D deficiency and respiratory morbidity among African American very low birth weight infants. Early Hum Dev 2018; 119: 19-24.

183. Curtis EM, Moon RJ, Harvey NC, Cooper C. Maternal vitamin $\mathrm{D}$ supplementation during pregnancy. $\mathrm{Br}$ Med Bull 2018; 126: 57-77.

184. Davies-Tuck M, Yim C, Knight M, Hodges R, Doery JC, Wallace E. Vitamin $D$ testing in pregnancy: does one size fit all? Aust N Z J Obstet Gynaecol 2015; 55: 149-55.

185. Garland CF, French CB, Baggerly LL, Heaney RP. Vitamin D supplement doses and serum 25-hydroxyvitamin $D$ in the range associated with cancer prevention. Anticancer Res 2011; 31: 607-11.

186. Imga NN, Berker D, Can B, Guler S. The effects of three regimens of cholecalciferol (vitamin D3) supplementation on vitamin $D$ deficiency in non-obese and obese females. Arch Med Sci Atheroscler Dis 2018; 3: e60-7.

187. Larque E, Morales E, Leis R, Blanco-Carnero JE. Maternal and foetal health implications of vitamin $D$ status during pregnancy. Ann Nutr Metab 2018; 72: 179-92.

188. Roth DE, Leung M, Mesfin E, Qamar H, Watterworth J, Papp E. Vitamin D supplementation during pregnancy: state of the evidence from a systematic review of randomised trials. BMJ 2017; 359: j5237. 